\title{
Problem Solving VS. Problem Formulating: Educational Implications of the Trinity Paradigm of Intelligence
}

Masoud Ghaffari ${ }^{1}$

\author{
${ }^{1}$ Department of Nursing and Health \\ Benedictine University, USA. \\ Email:mxghaff@msn.com
}

Licensed:

This work is licensed under a Creative Commons Attribution 4.o License.

Keywords:

Education

Human intelligence

Higher education

Teaching method

Problem solving

Problem formulating.

\begin{abstract}
The body of literature on human intelligence includes studies that stimulate human thinking and shed light on who we are as living entities and how we survive in complex situations. However, these studies lack one vital aspect of intelligence. What is lacking is an acknowledgement of the interconnectedness and interdependence of the embodied mind, human sociocultural and sociohistorical evolution, and transpersonal dynamics of who we are and how we make sense of our day-to-day living and enactment. Therefore, the intention of this research report is to explore a holistic approach to human intelligence and its implications for education in general and in mathematics education as an exemplar.
\end{abstract}

\section{Introduction}

Since the advent of psychometric ideology, the field of psychology, in general, and educational psychology has been occupied with materialization and objectification of the nature of intelligence. Implications of human intelligence based on the cognitive approaches has helped train students at different levels of education to become skillful workers. Globally, in the 21 st century, skillfulness alone is not enough for survival. In the post-modern era and beyond, with declining occupational opportunities due to automation, there arises a need for skillful workers who are critical thinkers, creative, intuitive, emotionally intelligent, responsible, moral, interdependent, and spiritual. Therefore, a unified concept of intelligence is needed for learning, understanding, and problem solving in this complex and ever-evolving world.

Gardner (1993) emphasizes multiple intelligences including logical-mathematical intelligence. Ceci (1990) in agreement with Vygotsky and his successors (e.g., Bronfenbrenner), believes that one's intelligence depends considerably on one's particular lifetime experiences. Jantsch (1989) self-organizing paradigm stresses the interconnectedness of natural dynamics at all levels of evolving micro and macro systems, which offers a new sense of meaning. Goody (1995) elaboration on evolving human intelligence points out that there is a growing view that intelligence evolves as a product of social interdependence. Sternberg (1985) triarchic theory explains the relationships among three different facets of intelligent behavior (i.e., individual's mental world, individual's experience, and individual's external world).

Another theory which can help us further our understanding of this complex process is autopoiesis. According to autopoiesis, proposed by Maturana (1981) the notion of cognition is extended to fully cover an organism's effective interactions. Acting is knowing, and knowing is acting (Mingers, 1985). Human beings are communal beings. Cobb (1990) contends that whereas the modern theories propose that each individual act from pure self-interest, the postmodern theory sees that communities are interdependent. Similar to Cobb's idea, the autopoietic principles emphasize the autonomy of the individuals and their interdependence on each other. Humanistic psychology emphasizes the human capacity for goodness, creativity, and freedom. Monte (1999) expresses that humanistic psychology construes the human being as a spiritual, rational, purposeful, and autonomous creature. Oregon Technology in Education Council (2007) summarizes and offers a composite definition of intelligence as a combination of the ability to:

- Learn. This includes all kinds of informal and formal learning via any combination of experience, education, and training.

- $\quad$ Pose problems. This includes recognizing problem situations and transforming them into more clearly defined problems.

- Solve problems. This includes solving problems, accomplishing tasks, fashioning products, and doing complex projects.

Although each of these theories may address some dimensions of intelligence, they lack a common-ground concept that includes all components of intelligence (i.e., intra-personal, inter-personal, and trans-personal). 


\section{Exploring a Holistic Approach}

Apart from many experts who believe that intelligence is what intelligence tests measure, a consensus based on review of literature points to three main themes: (a) the capacity to learn, (b) the total knowledge a person has acquired, and (c) the ability to adapt successfully to new situations.

From our perspective, a holistic approach notion of intelligence integrates and acknowledges the three themes while it requires the actor have a (humanistic) goal or purpose for such operation or enacting (derived from theory of autopoiesis). Intelligence, since ancient time, has been conceptualized and considered as one's potential or energy that will be actualized later during one's developmental process. The emerging Trinity Paradigm of Intelligence (Ghaffari, 2000) strongly supports this conceptualization. The theory embodies three components: (1) intrapersonal— physiological/psychological, (2) interpersonal—social/environmental, and (3) transpersonal-spiritual/beyond. The essence of 'interdependence' or interconnection inherently exists in each of these at different levels, from micro to macro.

The first category, intrapersonal, is within the realm of a person. Such a personal boundary encases and connects those elements that interact at the cellular, tissue, organ, and finally whole-body function. A subgroup of these relates to cognitive functioning such as a good organizer, analytic abilities, and mathematical abilities. Another subcategory relates to emotion functioning such as plans, passionate, and motivation. From integration of the cognitive and emotion functioning emerges the next subcategories which relate to learning and application of learned knowledge such as a continuous learner, ability to transfer knowledge from one context to another. From this state, the attributes such as creativity, imagination, and innovative sense would be nurtured and freed (Ghaffari, 2000).

The second category, interpersonal attributes, represents interdependence and interconnectivity between the individual and others/environment. Examples are a good friend, a good parent, articulate, artistic abilities, ability to relate to environment, adaptation, altruism, caring, commitment, and loyal (Ghaffari, 2000).

The third category is transpersonal. Interconnection of one to oneself and then to friends, family, community, society, environment, and ecosystem through a realization of a sense of wholeness enables one the freedom to get closer and ultimately unite with his or her spiritual essence. The attributes in this category univocally express realization such as having an art of living a human life, self-actualization, liberation of mind, and spirituality (Ghaffari, 2000).

This paper focuses on the implications of this holistic approach, TPI, in education. We discuss why such a holistic approach is needed for creativity and intuition in learning, and the events and situations that may impede their development. We start with a short discussion on problem solving followed by the importance of problem formulating. Then, we focus on the notion of emotion and intuition. We conclude this paper with final remarks on the implications of our proposed holistic approach for education in general and mathematics education as an exemplar.

\subsection{On Problem Solving}

Mathematical ability has been recognized repeatedly as a major category of human intelligence. This has been studied extensively from the psychometric and information-processing approaches to ability (Mayer, 1994). Psychological studies of higher order intellectual functioning have mainly focused on problem-solving strategies. There is increasing evidence that the higher level of mental operation involves a process of problem finding where creative thought has a great importance (Csikszentmihalyi, 1994). Due to the lack of a unified theory or an integrated, holistic theoretical concept of intelligence, many components and subcomponents of human intelligence functioning, including learning and mathematical abilities, have been partially investigated.

To explore the source of mathematics, Lakoff and Núñez (2000) examined the concept through multiple modalities (i.e., history of human evolution, cognitive science, culture, and neurobiology). They concluded that mathematics arises from our minds and our everyday experiences in the world. Human evolution and culture characterize the effectiveness of mathematics in the world, and that effectiveness results from a combination of mathematical knowledge and connectedness to the world. "Mathematics is a natural part of being human” (Lakoff \& Núñez, 2000).

Overall, there are four stages in problem solving: (a) understanding and representing the problem, or translating; (b) selecting the solution, or integrating; (c) executing the plan, or executing; and (d) evaluating the results, or planning /monitoring / reviewing. A critical element in solving problems in school is accurately representing the problem. To search for a solution, two general procedures are possible, algorithmic and heuristic (Mayer, 1994; Woolfolk, 1990).

Since Plato, the major rationale for the teaching of mathematics was the development of mental discipline. The concept of mentalism eventually died down due to the rise of behaviorism. However, years later, Piaget's work established the basis for a constructivist perspective. Then, there were Gestaltists who were interested in higher order thinking and problem solving. During the mid-1950s, information processing and its approach to cognition appeared. By the end of 1980s, the cognitive and sociocultural perspectives on human behavior were well on their ways. While the cognitive domain was focusing on knowledge of subject matter, concepts 
such as mathematics anxiety, student/teacher/general societal beliefs about doing mathematics were separated and designated to belong to the affective domain (Kilpatrick, 1987).

Development of mathematical thinking by emphasizing enhancement of conceptual knowledge (understanding) helps one to develop a broader perspective of his or her experiential world. While there is an abundance of research on mathematics problem solving and the related issues (National Council of Teachers of Mathematics, 2000a) the problem-finding matter has received very minimal and much less attention. Problem finding is an important constructive process.

\subsection{On the Importance of Problem Finding}

Csikszentmihalyi (1994) asserts that the process of problem finding consists of:

(1) it usually originates from an intrinsic desire to use a skill for its own sake, "without conscious aim," (2) as the skill begins to be used, an interaction arises between the person and the medium (drawing, sculpting, mathematics, music, chemical experimentation, and so on), and (3) the person, reacting to the results of this interaction, begins to organize and control consciously the emerging pattern, which may or may not suggest new possibilities and new problems. (p. 837)

The first systematic definition of problem finding was the work of Getzels cited in Csikszentmihalyi (1994) Getzels, after a broad review of related literature from Piaget to Guilford and Freud, developed a model that consisted of 10 problem types. The model started with the problems ranging from presented, discovered, and finally created problems. Brown (1993) and Kilpatrick (1987) are among the researchers who advocate and stress developing a problem-finding (formulating) strategy that promotes the formulation of new problems by changing the conditions of a current problem. "Most creative achievements involve fewer degrees of uncertainty and consist in finding either novel solutions, or developing new methods, or discovering new problems, but not all three" (Csikszentmihalyi, 1994). Teaching students what to think instead of how to think may hinder the development of their critical thinking, which is crucial in almost every life situation. In addition, it is also important to deepen the student's intuitive understanding of the various concepts and situations.

Davis (1995) stated that, "the key to a good solution is identifying the real problem that needs to be solved" (p. 1). To help mathematics education faculty to provide relevant educational experiences that prepare graduates for successful careers outside of academia, and to help industry make better use of the productive potential of mathematics, Davis (1995) conducted a study and interviewed 26 industrial mathematicians. While many students in fields such as mathematics and engineering capitalize on their learned formula and knowledge of specific subject matter in order to succeed in real life situations, what emerged from Davis' study revealed that the defining criteria for success are more cultural than purely intellectual.

\subsection{On the Notion of Emotion and Intuition}

Cognitive activity and emotional energy do occur together. The interactive feedback between them is used in our most effective thinking (i.e., intuition). Experience plays a fundamental role in shaping intuitions. Insight and intuition are referred to as "higher mental events" (Bastick, 1982). Monsay (1997) listed the following types of intuitions: physical, visual, spatial or geometric, sensible, kinesthetic, and intellectual. Bruner, cited in Noddings and Shore (1984) was one of a few educators who considered the important role of intuition in education. He defined intuition as the act of grasping the meaning/significance/structure of a problem without explicit reliance on analytic means. Similarly, Poincare, cited in Kilpatrick (1992) stated, "It is by logic that one proves, but it is by intuition that one invents" (p. 7).

What is the role of mathematics in one's transcendence? Visnu (Math: [OnLine]) stated that there was a common belief among ancient cultures that the laws of numbers have practical meaning as well as mystical and religious ones. For example, for Plato and Pythagoras the primary function of the intellect was spiritual realization, and mathematics first and for most was a spiritual activity (McFarlane, 1995). "Spiritually advanced cultures were not ignorant of the principles of mathematics, but they saw no necessity to explore those principles beyond that which was helpful in the advancement of God realization" (Visnu, 2002). One such culture is the ancient Indian civilization and its Vedic mathematics. Unlike Greek mathematics and its position that knowledge was for its own sake, in ancient India, mathematics served as a bridge between understanding material reality and the spiritual conception. Visnu elaborates on the gist of the Vedic worldview regarding the culture of knowledge, "While culturing transcendental knowledge, one can also come to understand the intricacies of the phenomenal world (p. 3).

Mathematical ability is one of the major categories of human intelligence. Intelligence is where our thinking, feeling, and acting originate. Since ancient time, the concept of intelligence has been a matter of interest and fascination for many researchers and philosophers.

\section{Implication of a Holistic Approach for Education}

Culture, social interaction, and communication have a profound impact on the development of human intelligence. Current research supports the claim that a child's home, school, and community help direct the child's intellectual development by providing and/or constraining the child's opportunities both to practice 
and develop specific intellectual skills, and to gain familiarity with and develop experience in a specific knowledge domain. Parents may contribute to their children's intellectual development through a genetic component, through direct interaction with the child, and through indirect communication. Schooling provides children with the opportunities to learn strategies for solving selected types of problems. The question many researchers are currently addressing concerns the ability to connect the skills learned in school to problems arising in other contexts, such as work environments.

Although there are many schools (public and private), many teachers, and students nationwide operating at the "optimum" level, statistics paint a bleak picture for the many more who are performing at below a "proficient” level (Ladson-Billings, 2001; Moses \& Cobb, 2001; NCTM, 2000b, 2000c).

What is the effect of education on one's intellectual development? There is an abundance of research that shows the relationships between a school's culture and students' achievements (D'Ambrosio, 2001) (Frankenstein, 1995) (NCTM, 2000b, 2000c; a. NCTM, 2001a) (Ogbu, 1987) (Secada, 1992). However, our conceptualization of intelligence is a holistic one. Therefore, our description and interpretation are much broader. Here, we are not considering one's achievement in school but achievement in life, survival and adaptations, prosperity and transcendence. Education, in general, does greatly affect one's intellectual development at all three of the constructed categories (i.e., intrapersonal, interpersonal, and transpersonal). Therefore, an inadequacy in education will directly ascribe to one's failure at school as well as in any other context. For many years, scientists focused most of their work on cognitive abilities. However, as explained earlier, it is impossible to separate cognition from emotion. This entire complex is like a web of connectivity and relationship, headed by the executive system in the prefrontal cortex. The prefrontal cortex is responsible for self-control, among many other things, and is closely linked to motor planning areas and to the emotional limbic system. Physical experience helps integrate the emotional and executive circuitry. Children need a multi-sensory and enriched environment to help them develop this complex system (Healy, 1998). Emotional contact plays a critical role in human learning. Strong emotional experiences, a kind word or an enthusiastic response from a teacher or parent, strengthen the memory of what is being learned.

People's current potentials and cognitive statuses are products of development in a very broad sense, involving several levels of regulation in interaction and transaction with each other, not one's cast in DNA or environments. In the social processes by which they arise, human potentials seemingly created by individuals, are actually the properties, not of individuals, but of all of us, and ones in which we can all share.

Transcendent enactment defined by Jourard (1966) as "a release of latent potentialities, of capabilities to perceive, invent, create, achieve, endure or perform . . . in most people these capacities lie buried under the 'crust' and inertia of habit, rigid role definitions and confining self-concepts" (p. 353). As discussed earlier, Trinity Paradigm of Intelligence posits that intelligence is comprised of the three components of intrapersonal, interpersonal, and transpersonal. They represent physical interdependence, social interdependence, and spiritual interdependence, respectively. Delineating the concept further, for entities to be considered intelligent they must be in the process of initiating interdependence, establishing interdependence, or supporting and maintaining interdependence at each state of embedding. In our schools and society, each step of this process requires a knowledgeable teacher and/or caregiver who can provide adequate physical, social, and spiritual opportunities.

Competition and individualism have been topics of debates and arguments among members of different cultures. The point we would like to make is that competition along with mutualism has been and will be the secret to survival of members within and in between species. However, when such competition and individualism refer to self-survival at the cost of ignoring others' rights and jeopardizing others' existence, then it becomes pathologic. Salingaros (1998) explains, "A central component of the human intellect is the ability to establish connections" (p. 2).

Taking into consideration the above, what would be the characteristics of an educated person of $21^{\text {st }}$ century? Schafer and Amenta (1992) suggest the following: the educated person of the future should embody such virtues as holism, altruism, and environmentalism, and should be creative, cooperative, circumspect, and egalitarian. Our perspective on a holistic approach to human intelligence helps in the cultivation of all these events and helps one to transcend. Humans possess energy or potential (intelligence), which through the process of becoming, will be actualized. The goal or the purpose is simple and clear. Yet, its process is very complex. we have learned a lot about problem-solving and about intelligence by constructing computer models of how to play games, and simulation. However, this does not mean that we are able to build models of how to cope with the real world. Problem formulation is the creative and probably the more important step towards overcoming a problematic state than problem-solving. A good definition of what the problem is, "is believed to be more than half of the way towards is eventual elimination."

\section{Contributions of TPI to Education}

We know that the problem-solving skills are important since we all must make decisions on a daily basis. An important goal of education is helping students learn how to think more productively while solving problems, by combining creative thinking (to generate ideas) and critical thinking (to evaluate ideas). Both modes of thinking are essential for a well-rounded productive thinker, according to experts in both fields 
(Rusbult, 2018). Critical thinkers must be creative thinkers as well, generating possible solutions to find the best one. Educators should want to design instruction that will help students improve their thinking skills. To more effectively help students improve their problem-solving skills, teachers can provide opportunities for students to be actively involved in solving problems, with "inquiry activities." Opportunities for inquiry occur whenever a gap in knowledge stimulates action (mental and/or physical) and students are allowed to think-dolearn. One model is "design-inquiry" in which students try to improve some other aspect(s) of life, by defining problem-projects (problem formulation) and seeking solutions. Understanding and acknowledging the "other" aspects of life, besides the main topic/science, requires developing a holistic thinking and holistic intelligence. Also, creative or innovative thinking, the kind of thinking that leads to new insights, novel approaches, fresh perspectives, whole new ways of understanding and conceiving of things requires developing a holistic intelligence, e.g., TPI. A blending of creativity and critical thinking is necessary for productive thinking that produces a high-quality solution for a problem. But creativity can be hindered by its interactions with critical thinking, for reasons that are psychological and/or sociological, affecting individuals and groups. Trinity Paradigm of Intelligence help students to become creative and critical thinkers by understanding "interdependence", the core of it all. This allows students to go beyond "problem-solving" and to "formulate problem" by: establishing the context, laying out the alternatives, predicting the consequences, valuing the outcomes, and making a choice or the preferred course of action.

\section{Conclusions}

It is important to consider and understand the implications the TPI has for teaching and learning according to its core in that: (a) all learning and understanding is inherently cultural and social activity of people; (b) an individual is an organizationally closed entity, which means the individual has his or her identity because the individual is an autonomous entity who has a history of interactions and communication with his or her surroundings; and (c) a holistic approach to education includes an embodied mind, feeling, enactment, and interdependence. In this sense, an intelligent being recognizes and values the importance of relationship, connectivity, and responsiveness to others' needs. Developing such sensitivities and understandings enables one to become more proactive and see his or her co-existence with the other beings.

\section{References}

Bastick, T. (1982). Intuition: How we think and act. New York: John Wiley \& Sons.

Brown, S. (1993). Problem posing in mathematics education. SI Brown ve MI Walter (Eds.), Problem posing: reflection and applications (pp. 16-27). Hillsdale, NJ: Lawrence Erlbaum Associates.

Ceci, S. J. (1990). On intelligence ...more or less: A bio-ecological treatise on intellectual development (pp. 12-36). Englewood Cliffs, NJ: Prentice Hall Century Psychology Series.

Cobb, J. B. (1990). From individualism to persons in community: A postmodern economic theory. In D. R. Griffin (Ed.), Sacred interconnections: Postmodern spirituality, political economy, and art. New York: State University of New York Press. pp: 123-143.Csikszentmihalyi, M., 1994. Creativity. In R. J. Sternberg (Eds.), Encyclopedia of human intelligence (pp. 836-840). New York: Macmillan Publishing.

Csikszentmihalyi, M. (1994). Creativity. In R. J. Sternberg (Eds.), Encyclopedia of human intelligence (pp. 836-840). New York: Macmillan Publishing.

D'Ambrosio, U. (2001). What is ethnomathematics, and how can it help children in schools? Teaching Children Mathematics, $7(6), 308-310$.

Davis, P. W. (1995). Finding the real problem. Retrieved from https://www.siam.org/.

Frankenstein, M. (1995). Equity in mathematics education: Class in the world outside the class. In W.G., Secada, E. Fennema and L.B., Adajjan (Eds.) New Directions for Equity in Mathematics Education. Cambridge: Cambridge University Press

Gardner, H. (1993). Frames of mind: The theory of multiple intelligences. New York: Basic Books.

Ghaffari, M. (2000). Intelligence: E pluribus unum. An ontological and epistemological inquiry. Ph.D. Dissertation, Cleveland State University, United States-Ohio. Publication No. AAT 9995573.

Goody, E. N. (1995). Social intelligence and interaction: Expressions and implications of the social bias in human intelligence. Cambridge, MA: Cambridge University Press.

Healy, J. M. (1998). Failure to connect: How computers affect our children's minds, for better and worse. New York: Simon \& Schuster, Humanities Press International.

Jantsch, E. (1989). The self-organizing universe: Scientific and human implications of emerging paradigm of evolution. Elmsford, NY: Pergamon Press.

Jourard, S. (1966). Toward a psychology of transcendent behavior. In H.A., Otto (Ed.), Explorations in Human Potentialities (pp. 349-377). Springfield, IL: Charles C. Thomas Publisher.

Kilpatrick, J. (1987). Problem formulating: Where do good problems come from. In A. H., Achoenfeld (Ed.), Cognitive Science and Mathematics Education (pp. 123-147). Hillsdale, NJ: Lawerence Erlbaum.

Kilpatrick, J. (1992). A history of research in mathematics education. In D.A. Grouws (Eds.), Handbook of research on mathematics teaching and learning (pp. 3-39). New York: Macmillan Publishing.

Ladson-Billings, G. (2001). It doesn't add up: African American students' mathematics achievement. Challenges in the mathematics education of African American children. Reston, VA: NCTM.

Lakoff, G., \& Núñez, R. E. (2000). Where mathematics comes from: How the embodied mind brings mathematics into being (pp. 10-12). New York: Basic Books. 
Maturana, H. R. (1981). Autopoiesis. In M. Zeleny (Ed.), Autopoiesis: A theory of living organization (pp. 21-23). New York: Elevie-North Holland.

Mayer, R. E. (1994). Mathematical ability. In R. J. Sternberg (Eds.), Encyclopedia of human intelligence (pp. 840-845). New York: Macmillan Publishing.

McFarlane, T. J. (1995). The spiritual function of mathematics. Retrieved from http://www.integralscience.org/sacredscience/SS_spiritual.html.

Mingers, J. (1985). Self-producing system. New York: Plenum.

Monsay, E. H. (1997). Intuition in the development of technology and physical theory. In Davis-Floyd, R. E Arvidson, P. S. (Eds.), Intuition: The inside story, interdisciplinary perspectives. New York: Routledge.

Monte, C. F. (1999). Beneath the mask: An introduction to theories personality. Orlando, FL: Harcourt Brace College Publishers.

Moses, R. P., \& Cobb, C. E. (2001). Radical equations: Math literacy and civil rights. Boston: Beacon Press.

National Council of Teachers of Mathematics. (2000a). Principles and standards for school mathematics. Reston, VA: NCTM.

NCTM. (2000b). Changing the faces of mathematics, perspectives on African Americans. Reston, VA: NCTM.

NCTM. (2000c). Changing the faces of mathematics, perspectives on multiculturalism and gender equity. Reston, VA: NCTM.

NCTM, a. (2001a). Challenges in the mathematics education of African American children. Proceedings of the Benjamin Banneker Association Leadership Conference, Reston, VA.

Noddings, N., \& Shore, P. J. (1984). Awakening the inner eye: Intuition in education. New York: Teachers College Press.

Ogbu, J. U. (1987). Variability in minority school performance: A problem in search of an explanation. Anthropology $\mathcal{E}^{\circ}$ Education Quarterly, 18(4), 312-334.

Oregon Technology in Education Council. (2007). Theories of intelligence. Retrieved from http://otec.uoregon.edu/intelligence.htm.

Rusbult, C. (2018). Problem solving \& metacognition in education and life. Retrieved from https://www.asa3.org/ASA/education/think/education.htm.

Salingaros, N. A. (1998). Theory of the urban web. Journal of Urban Design, 3(1), 53-71.

Schafer, P. D., \& Amenta, S. A. (1992). An image of the educated person of the future: Contribution of education to cultural development. Paper presented at the Paper Presented at the United Nations Educational, Scientific, and Cultural Organization International Conference on Education. Geneva, Switzerland. ERIC Document Reproduction Service No. ED366 541 .

Secada, W. G. (1992). Race, ethnicity, social class, language, and achievement in mathematics. In D. A. Grouws (Ed.), Handbook of research on mathematics teaching and learning (pp. 623-660). New York: Macmillan.

Sternberg, R. J. (1985). Beyond IQ: A triarchic theory of human intelligence. New York: Cambridge University Press.

Visnu, B. B. (2002). Mathematics and the spiritual dimension. Retrieved from http://www.gosai.com/chaitanya/saranagati/html/math/math_1.html.

Woolfolk, A. E. (1990). Educational psychology. Englewood Cliffs, NJ: Prentice-Hall. 